American J. of Engineering and Applied Sciences 4 (1): 153-161, 2011

ISSN 1941-7020

(C) 2010 Science Publications

\title{
Measuring the Resiliency of the Manhattan Points of Entry in the Face of Severe Disruption
}

\author{
Mayada Omer, Ali Mostashari and Roshanak Nilchiani \\ Center for Complex Adaptive Socio-technological Systems, \\ School of Systems and Enterprises, Stevens Institute of Technology, \\ Castle Point on Hudson, Hoboken NJ 07030-5991, USA
}

\begin{abstract}
Problem statement: Resilient infrastructure systems are able to continue to provide the expected service levels following disruptive events. Implementing resiliency in infrastructure systems requires knowledge of the current resiliency of the system and a methodology by which different resiliency strategies can be evaluated. In the transportation infrastructure in particular, disruptions cause delays, which will in turn incur substantial economic losses and environmental damages. Approach: The Networked Infrastructure Resiliency framework (NIRA) is proposes to assess the resiliency of the road network that connects Manhattan in New York City to the rest of the regions. The framework proposes to create a network model of the system onto which hypothetical disruptions can be introduced and then to measure resiliency as the impact of disruptions on the performance measures of the system. One of the key performance measures of the transportation infrastructure system is the travel time; hence, the base resiliency of the system is measured as the ratio of the travel time preceding a disruption to the travel time following a disruption. Different resiliency strategies that improve the system's resiliency can be evaluated through the use of decision tree analysis. Results: The proposed NIRA framework is a novel approach for assessing the resiliency of networked infrastructure system by measuring the impact of disruptions on the system's performance measures. In road transportation networks, such as that connecting Manhattan entry points, resiliency is achievable through reducing the vulnerability of the system and increasing its adaptive capacity. Conclusion: One vulnerability reduction strategy is the clever assignment of vehicles to other routes in the network. The adaptive capacity of the system is enhanced through the deployment of other parallel systems such as ferries.
\end{abstract}

Key words: Manhattan points, Resiliency infrastructure systems, decision trees

\section{INTRODUCTION}

The issue of infrastructure resiliency has been receiving an increasing amount of interest as a result of the devastating events of September 11th and Hurricane Katrina. Recently, under the Obama-Biden administration the Department of Homeland Security and other sector partners are implementing the National Infrastructure Protection Plan (NIPP) (Chertoff, 2009; Lee, 2008) that aims at "A safer, more secure and more resilient America".

Resiliency deals with the ability of the system to react to major threats or shocks. Therefore, creating resiliency in infrastructure systems entails first the identification of the infrastructure vulnerabilities and then the investigation of the different options that reduce the vulnerabilities and increase the adaptive capacity by providing means to the infrastructure to resume regular operations whilst minimizing losses.
The transportation infrastructure is particularly vulnerable to environmental hazards such as heavy snowstorms or floods that temporarily immobilize functionality whilst causing structural damages. Accidents and road works often cause road obstructions that create delays. Additionally, human error and natural factors can result in mechanical failures such as the collapse of bridges and tunnels that not only leads to substantial travel time delays but also the loss of human lives.

The island of Manhattan in New York is home to more than $1.6 \mathrm{~m}$ people. Since it is the business and commercial center of New York City, the number of people in Manhattan swells to more than 4 million people during the day. Although a significant number of travelers opt for public transport, the bridges and tunnels that connect Manhattan still carry an average of 90,000 vehicles per $\mathrm{h}$ in both directions. Also, since

Corresponding Author: Mayada Omer, Babbio Centre 5th Floor, School of Systems Engineering and Enterprises,

Stevens Institute of Technology, Castle Point on Hudson, Hoboken NJ 07030-5991, USA 
Manhattan is an island, the only access for vehicles into Manhattan is through the tunnels and bridges; transportation of goods such as food supplies into Manhattan is primarily by the use of trucks over the tunnels and bridges.

In this study, first a network model of the road network surrounding Manhattan is developed unto which disruptions in the form of road capacity reduction can be imposed. The network model is made up of links and nodes where the links represent the entry points of Manhattan and the nodes are the regions that are connected via the tunnels and bridges. The traffic flow of the network is estimated by a network optimization problem that utilizes realistic demand and capacity values of the network. Then we look at resiliency measures that are applicable to this particular transport infrastructure system and evaluate the resiliency strategy through the use of decision trees.

The methodology allows decision-makers to identify the most critical segments in a transportation network and identify strategies to improve the resilience of such networks. The methodology is applicable to other types of transportation networks and can also be modified to other networked infrastructure systems such as energy and telecommunication systems.

Literature review: A number of studies have focused on infrastructure resiliency in general and transport resiliency in particular and there are many interpretation of resiliency. The general essence is that resiliency is the ability of the system to bounce back after a shock and return back to its normal value delivery levels. Enhancing the infrastructure resiliency creates the need for metrics that assess the current resiliency of the system. The metrics offer the stakeholders the opportunity to evaluate the resiliency of the current infrastructure and to evaluate the effectiveness of the resiliency enhancement strategies. For infrastructure systems, Bruneau and Reinhorn (2007) proposed a metric for measuring the resiliency of infrastructures as the expected degradation of the quality of the infrastructure over time. Omer et al. (2009) proposed a metric for networked infrastructure systems as the ratio of the value delivery of a network after a disruption to the value delivery before a disruption.

Resiliency metrics have also been defined for service infrastructures. In power and water infrastructures, Chang and Chamberlain (2003) measured resiliency in terms of economic loss, Shinozuka and Chang (2004) measure the resiliency of power systems in terms of speed of restoration and repair efficiency. In the telecommunication infrastructure, Cohen et al. (2001) studied the tolerance of the Internet to intentional attack; they proposed a resiliency metric as a measurement of the number of sites needed for the disintegration of the network.

In the field of transport infrastructure, Werner (1998) measure the resilience as the increase of travel time preceding a disruption. Murray-Tuite (2006) proposed metrics for evaluating the ten components of the transport infrastructure resiliency and compares the system optimum and user equilibrium traffic assignments. Heaslip et al. (2009) categorize the metrics with regards to the transportation infrastructure into individual resiliency, community resiliency, economic resiliency and recovery metrics; each metric is evaluated as a combination of several indices that describe each metric.

In this study, resiliency is measured in terms of the impact of disruptions on the system's performance measures; a service disruption in one of the bridges or tunnels would cause traffic congestions that result in an increase in travel time that is used to calculate the travel time resiliency; it is possible to identify several resiliency metrics that measure other network performance measures that are influenced by the disruptive event. The proposed resiliency metric is used to measure the node-to-node resiliency as well as the system wide resiliency for the duration of the disruptive event since road disruptions can last up to several hours or even several days. The node-to-node resiliency metric measures the resiliency between any two nodes that are directly connected to the disrupted link. The system wide resiliency measures the impact of one or more link disruptions on the overall network travel time.

Network resiliency assessment framework: The disruptions on tunnels and bridges that cause the structure to collapse will often lead to substantial negative socioeconomic impacts since in most cases the tunnel or bridge is the primary if not the only access point. Tilahunm and Levinson (2008) studied the impact of the collapse of the I-35W in Minnesota in 2007 on the daily activity of the users of the bridge, they concluded that most bridge users adopted new routes and adjusted their travel time according to traffic on their planned routes. The bridge collapse also resulted an economic loss of $\$ 17$ million and $\$ 43 \mathrm{~m}$ in 2007 and 2008 respectively (DOT 2009). In cases of such severe disruptions, passenger safety becomes an issue of primary concern; there is therefore a need for making transportation system less susceptible to disruption by continually monitoring their health to ensure passenger safety. Studies by Chan and Mehta 
(2010) showed that implementation of fiber optic sensors for monitoring the health of transportations systems minimizes downtime, avoids catastrophic failures and reduces maintenance and labor. These factors are key issues in achieving a resilient infrastructure system.

The severe impacts of disruptions on tunnels and bridges create a need for enhancing the resiliency of the road transportation systems, which in turn creates a need for metrics. In this study, we propose the Networked Infrastructure Resiliency Assessment (NIRA) framework that enables the stakeholders to assess the resiliency of the system under various disruptive scenarios. Using the framework, it is possible to identify the most critical segment in the network and to evaluate the benefits of the proposed resiliency strategies.

The framework is made up of several steps that start with the specification of the system boundary and end with the evaluation of the identified resiliency strategies. The first step is to determine the system boundary, that is, the physical and temporal boundaries of the analysis. The second step is to identify the performance measures of the system; these are those parameters that are affected by the disruptions. The identified parameters determine the resiliency metrics of the system. Next, the system under study can be modeled as a network that is made up of links and nodes unto which the network flow is determined based on the demand and capacity data. The following step is to evaluate the network and node-to-node resiliency under normal operating conditions. Since resiliency is the ability of the system to cope with disruptions, hypothetical disruptions are introduced to the network by using various disruptive scenarios in the from of reducing the link capacities so that the impact of the disruptions on the system performance can be evaluated. The final steps are to identify resiliency strategies that enhance the resiliency of the system and then to evaluate these strategies using decision analysis tools. Fig. 1 shows the general structure of the framework.

\section{Application of the NIRA framework on Manhattan's entry points:}

System boundary: The physical boundary of the network model includes the bridges and tunnels that connect the island of Manhattan to the outside world as well as the road network that links the entry points outside of Manhattan. Temporal boundaries define the time frame of the analysis. For this particular network the resiliency is measured for the time period between 7 am and $10 \mathrm{pm}$.

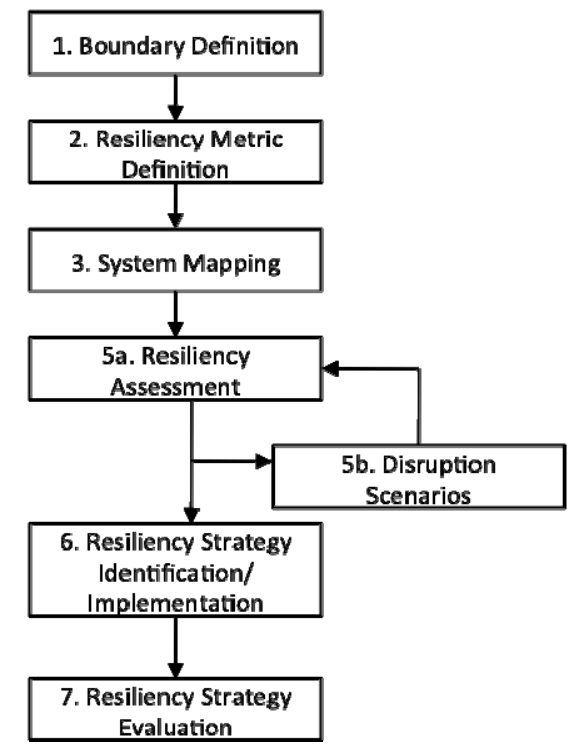

Fig. 1: Networked Infrastructure Resiliency Assessment (NIRA) framework

Resiliency metric definition: The system's resiliency is determined by its performance measures. The disruptions faced by this infrastructure system such a road works, floods, accident or mechanical failures that could result in the collapse of the entry points will result in prolonged travel times. Therefore, the network travel time was identified as resiliency metric of the system.

The network travel time resiliency $R_{t \text { network }}$ of the network can be measured as the ratio of the network travel time preceding a disruption the network travel time following a disruption as shown in Eq. 1.

$\mathrm{R}_{\mathrm{t}_{-} \text {network }}=\frac{\mathrm{t}_{\mathrm{n} \text { (before shock) }}}{\mathrm{t}_{\mathrm{n} \text { (after shock) }}}$

Where:

$\mathrm{t}_{\mathrm{n}}=$ The network travel time

$\mathrm{t}_{\mathrm{ij}}=$ The travel time from node $\mathrm{i}$ to node $\mathrm{j}$

The node-to-node travel time resiliency $R_{t \text { node }}$ is the ratio of the travel time between the two nodes $i$ and $j$ preceding a disruption to the travel time between the two nodes following a disruption. The node-to-node resiliency measured is shown in Eq. 2.

$\mathrm{R}_{\mathrm{t}_{\text {_node }}}=\frac{\mathrm{t}_{\mathrm{ij} \text { (before shock })}}{\mathrm{t}_{\mathrm{ij}(\text { after shock })}}$

Where:

$\mathrm{t}_{\mathrm{n}}=$ The network travel time

$\mathrm{t}_{\mathrm{ij}}=$ The travel time from node $\mathrm{i}$ to node $\mathrm{j}$ 
The network or node-to-node resiliency over a specified time period $(t)$ is measured using Eq. 3.

$$
\mathrm{R}=\frac{\int_{0}^{\mathrm{t}} \mathrm{R}_{\mathrm{t}}(\mathrm{t}) \mathrm{dt}}{\Delta \mathrm{t}}
$$

Using these resiliency metrics, it is possible to evaluate the damage when a link is partially or completely disrupted. The resiliency has a value of 1 under normal network operations and approaches 0 as the travel time increases to infinity.

System mapping: This step involves obtaining a logical network from the physical network. Fig. 2 shows the main bridges and tunnels that connect Manhattan. For the sake of simplicity, the smaller East Harlem River bridges have not been taken into consideration.

The network shown in Fig. 2 can be mapped as a directed logical network. The nodes in the network represent the area that is connected to Manhattan via the entry points, the network links represent the bridges and tunnels that lead to Manhattan as well as the major intersections that connect the road network that connect the entry points. The resultant network is made up of 14 nodes and 25 directed links. The logical network is shown in Fig. 3.

Network flow analysis: Analytical quantification of the network requires the knowledge of the demand and capacity of the network. The capacity and demand data are used to determine the flow, which will in turn be used to calculate the travel time.

The network demand for this network is the total number of vehicles per hour that are travelling into Manhattan via the bridges as well as the regular traffic on the roads connecting the bridges. The demand is based on numbers provided by the New York State Department of Transportation (2009) and State of New Jersey Department of Transport (2009).

The links in the network represent different types of roads. The highway capacity is based on the 2000 Highway Capacity Manual ( Transportation Research Board, 2000; United States Environemntal Protectiona Agency, 2000). The calculations take into account the speed limits imposed on the highways and arterials that make up the network as well as truck and heavy vehicle traffic. It should be noted that these travel demand and capacity numbers represent a grossly oversimplified approximation; more accurate numbers can be obtained by using intercity demand models. However, since the focus of this study is the assessment of resilience, the travel demand and road capacities are a given input into the optimization problem.

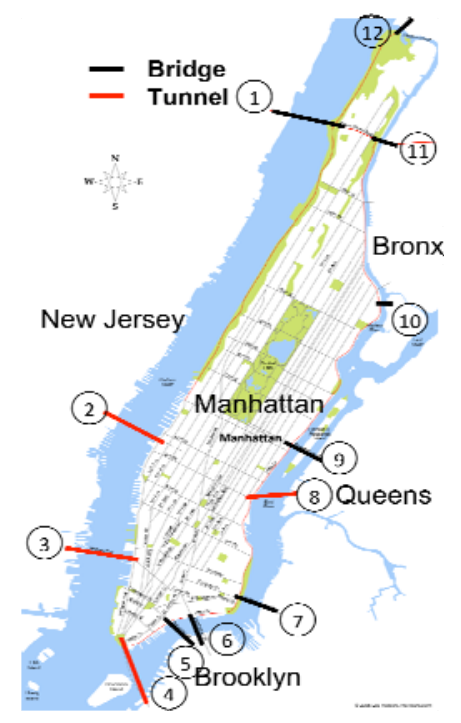

Fig. 2: Main entry points of the island of Manhattan source: iNETours.com; 1: George Washington Bridge; 2: Lincoln Tunnel; 3: Holland Tunnel; 4: Brooklyn Battery Tunnel; 5: Brooklyn Bridge; 6: Manhattan Bridge; 7: Williamsburg Bridge; 8: Queens-Midtown Tunnel; 9: Queensborough Bridge; 10: Triborough Bridge; 11: Alexander Hamilton Bridge; 12: Henry Hudson Bridge

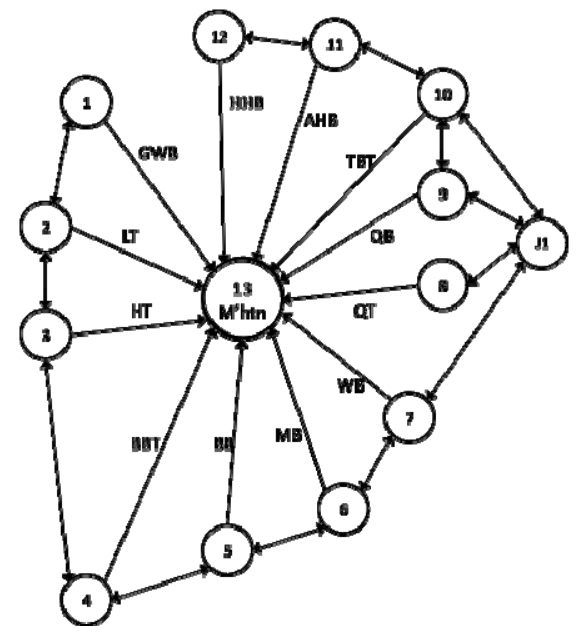

Fig. 3: Logical network of main entry points of the island of Manhattan; GWB: George Washington Bridge; LT: Lincoln Tunnel; HT: Holland Tunnel; BBT: Brooklyn Battery Tunnel; BB: Brooklyn Bridge; MB: Manhattan Bridge; WB: Williamsburg Bridge; QT: Queens-Midtown Tunnel; QB: Queensborough Bridge; TB: Triborough Bridge; AHB: Alexander Hamilton Bridge; HHB: Henry Hudson Bridge; M'HTN: Manhattan 
The network flow is the number of vehicles per hour travelling into Manhattan and the number of vehicles per hour travelling in the rest of the network links. The optimal flows of the network can be calculated by minimizing total network travel time provided that the demand is met. The segment travel time between any two nodes is calculated using the Bureau of Public Roads (BPR) function developed by Horowitz (1991), the function shown in Eq. 4 measures the travel time in congested traffic. The BPR function is the most commonly used relationship for estimating the travel speed due to increasing in travel volumes:

$t_{i j}=\frac{1_{i j}}{\text { free flow speed (mph) }} \times\left[1+0.15\left(\frac{x_{i j}}{c_{i j}}\right)^{4}\right]$

Where:

$\mathrm{t}_{\mathrm{ij}}=\quad$ The time it takes to travel between node $\mathrm{i}$ and node $\mathrm{j}$

$1_{i j}=$ The length of the link between node $i$ and node $j$

$\mathrm{x}_{\mathrm{ij}}=$ The flow between node $\mathrm{i}$ and node $\mathrm{j}$

$\mathrm{c}_{\mathrm{ij}}=$ The capacity of the link between node $\mathrm{i}$ and node $\mathrm{j}$

Since a reduced travel time is more desirable, the objective function is to minimize the travel time of all the links in the network. The network optimization problem is shown in Eq. 5-13.

Min $t_{n}$

Subject to the constraints:

$$
\begin{aligned}
& \sum_{j=1}^{n} x_{s j}=D_{s} \\
& \sum_{i=1}^{n} x_{i j}+\sum_{j=1}^{n} x_{j i}=0
\end{aligned}
$$

$\sum_{i=1}^{n} x_{i t}=D_{s}$

$\mathrm{z}_{\mathrm{ij}}=\mathrm{x}_{\mathrm{ij}}+\mathrm{D}_{\mathrm{ij}}$ for $\mathrm{i} \neq \mathrm{s}$

$c_{i j}=\alpha_{i j} c_{i j}$

$\mathrm{t}_{\mathrm{ij}}=\frac{\mathrm{1}_{\mathrm{ij}}}{\text { free flow speed }(\mathrm{mph})} \times\left[1+0.15\left(\frac{\mathrm{x}_{\mathrm{ij}}}{\mathrm{c}_{\mathrm{ij}}}\right)^{4}\right]$

$$
t_{n}=\frac{\sum_{i=1}^{n} \sum_{j=1}^{n} D_{i j} t_{i j}}{\sum_{i=1}^{n} \sum_{j=1}^{n} D_{i j}}
$$

$$
\mathrm{x}_{\mathrm{ij}} \geq 0
$$

Where:

$\mathrm{t}_{\mathrm{n}}=$ The network travel time

$\mathrm{D}_{\mathrm{s}}=$ The demand on the disrupted link

$\mathrm{x}_{\mathrm{sj}}=$ The flow out of the source node $\mathrm{x}_{\mathrm{ij}}=$ The flow into a node in the network carrying demand of disrupted link $\mathrm{x}_{\mathrm{ji}}=$ The flow out of a node in the network carrying demand of disrupted link

$\mathrm{x}_{\mathrm{it}}=$ The flow into the destination node (Manhattan)

$\mathrm{c}_{\mathrm{ij}}=$ The link capacity before disruption

$\mathrm{C}_{\mathrm{ij}}=$ The link capacity after disruption

$\alpha_{i j}=$ The capacity degradation coefficient

$z_{\mathrm{ij}}=$ The network flow after a disruption $1_{i j}=$ The length of the segment between node $\mathrm{i}$ and node $\mathrm{j}$

$\mathrm{t}_{\mathrm{ij}}=$ The time it takes to travel from node $\mathrm{i}$ to node $\mathrm{j}$

$D_{i j}=$ The demand from node $\mathrm{i}$ to node $\mathrm{j}$

$\mathrm{n}=$ The number of links connected to a node

Equation 6 ensures that the flow exiting from source node (end of disrupted bridge outside of Manhattan) is equal to the demand between the disrupted bridge and the destination (Manhattan). Equation 7 sets the mass balance constraint, that is, the flow into the nodes between the source and destination nodes is equal to the flow out of the node and Eq. 8 ensures that the flow reaches the destination node (Manhattan). Equation 9 is the final flow of the network that includes the regular traffic in the network in addition to the traffic between the source and the destination. Equation 10 determines the current capacity of the links in the network through the adjustment of co-efficient $\alpha_{\mathrm{ij}}$. Equation 11 is the BPR function for calculating travel time.

Disruption scenarios: The impact of disruption to any link in the network on the resiliency values is evaluated using the model. In road networks, disruptions reduce road capacities and cause delays. The impact of capacity reduction can be modeled by the introduction of hypothetical disruptions through the coefficient $\alpha_{\mathrm{ij}}$ shown in Eq. 10. The network is made to operate at full capacity through setting the value of $\alpha_{\mathrm{ij}}$ to 1 . A value of 0.5 will reduce the link capacity by $50 \%$, a value of 0.3 reduces the link capacity to $30 \%$ and so on. Total road blockage can be modeled by setting the value of $\alpha_{\mathrm{ij}}$ to 0 . Resiliency over a prolonged time period can be calculated by including the effect of demand values to include peak and off-peak traffic throughout the day. 
Resiliency strategy identification: Resiliency is achievable by taking proactive measures prior to a disruption and reactive measures preceding a disruption. The usage of Intelligent Transport System (ITS) enhances the reactive resiliency measures of the system by measuring the demand and volume in the network and recommending alternative routes whilst minimizing travel time delays.

Proactive measures are implemented prior to disruptive events and are deployed after the occurrence of the disruption so that normal operation can be resumed. This can be in the form of promoting the deployment of parallel systems such as ferries and trains in cases of severe disruptions to reach the destination. Ferries are frequently used as a mode of transport to and from Manhattan; in the cases of severe disruptions the usage of ferries where required through the conversion of ferries that would otherwise transport goods into passenger vehicles or using the unused fleet of passenger ferries can generally provide an efficient commute between the source and the destination.

Resiliency strategy evaluation: Implementation of the above mentioned strategies requires a structured decision analysis process by which decision makers can choose between the alternative strategies and also to evaluate the cost effectiveness of the strategy. Decision tree analysis is a commonly used tool to calculate the expected value of the alternatives under uncertainty.

Figure 4 shows the decision tree of the expected outcomes with and without a resiliency strategy. If the probability of the occurrence of the disruptive event is $\rho$, the probability of non-occurrence is $\rho-1$. In the case of a disruptive event, implementation of the resiliency strategies has the associated costs of $\mathrm{C}_{\mathrm{i}}$ as the cost of the investment, $\mathrm{C}_{\mathrm{o}}$ as the cost of operation and $\mathrm{C}_{\mathrm{r}}$ as the financial loss incurred due to the disruptive event with the resiliency strategy. If no resiliency strategy is implemented and a disruption occurs, the financial loss due to the disruption is $\mathrm{C}_{\mathrm{s}}$.

The decision tree is used to calculate the net present value NPV at the decision node over a number of $\mathrm{N}$ periods using the dicscount rate $r$ is shown in Eq. 14:

$\mathrm{NPV}_{\mathrm{RES}}=\sum_{\mathrm{i}=1}^{\mathrm{N}} \frac{\rho\left(\mathrm{C}_{\mathrm{s}}-\mathrm{C}_{\mathrm{o}}-\mathrm{C}_{\mathrm{r}}\right)-\mathrm{C}_{\mathrm{i}}}{(1+\mathrm{r})^{\mathrm{i}}}$

It is worth pursuing the implementation of the resiliency strategy if the value of the NPV is higher than the investment $\operatorname{cost} \mathrm{C}_{\mathrm{i}}$.

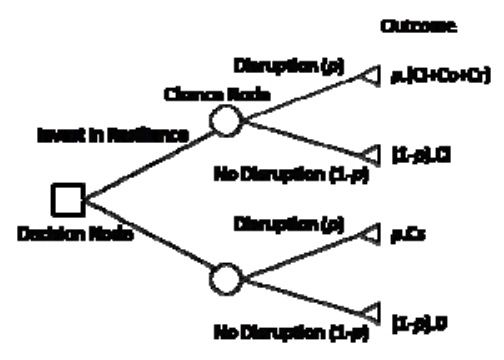

Fig. 4: Decision tree for evaluating resiliency strategies

\section{MATERIALS AND METHODS}

Resiliency assessment: The methodology of the NIRA process was applied to the bridges and tunnels that connect to Manhattan, NY. The model was programmed in Excel and the program Solver was used to execute the model. Equations 5-13 were applied to determine the flow and to introduce hypothetical disruption to the model and to calculate the network travel time. Equation 1 and 2 were used to determine the network travel time resiliency and node-to-node resiliency respectively.

Under normal operating conditions, the resiliency value is 1. Capacity disruptions result in an increase in travel time, which reduces the value of the network resiliency. Figure 5 shows the impact of the reducing the capacity of each link by $20 \%$ on the node -to-node resiliencies at peak traffic.

The graph shows that a reduction of road capacity of only $20 \%$ has an impact on the node-to-node travel time. This result indicates that the network with its current capacity is extremely vulnerable to disruptions. In some cases such as the Holland Tunnel, reducing the capacity by $20 \%$ results in a resiliency value of 0.55 , this means that the travel time almost doubles.

One vulnerability reduction strategy is to route the traffic over the other links in the network. With prior knowledge of the disruption, vehicles travelling into Manhattan Holland Tunnel will choose to travel over other entry points. Figure 6 shows a comparison of the node-to-node resiliency values with and without a vulnerability reduction strategy.

Re-routing the vehicles over other routes in the network improved the node-to-node resiliencies of the Holland Tunnel and the Queens-Midtown Bridge. In other cases, the resiliency has the same value; this is due to the rerouted vehicles causing traffic to congest elsewhere. Figure 7 shows the impact of disrupting the Holland Tunnel link on the network travel time. Total link disruption reduces the network travel time resiliency by $10 \%$. 
Am. J. Engg. \& Applied Sci., 4 (1): 153-161, 2011

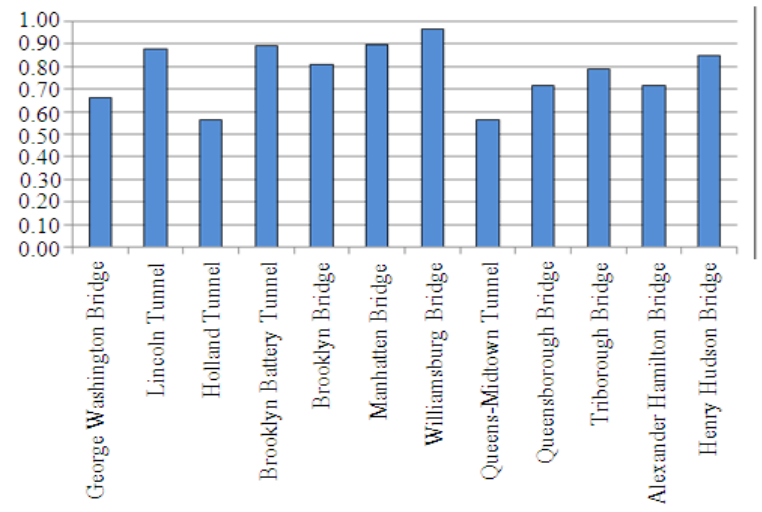

Fig. 5: Node to node resiliency at $80 \%$ capacity

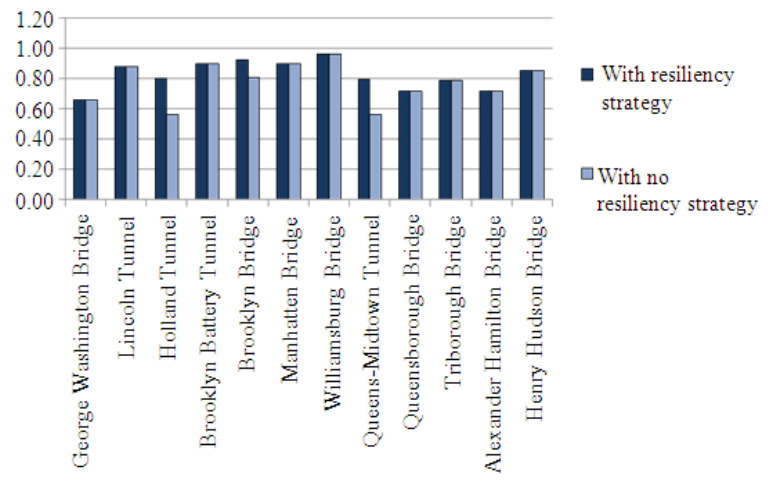

Fig. 6: Node to node resiliency at $80 \%$ capacity with resiliency strategy

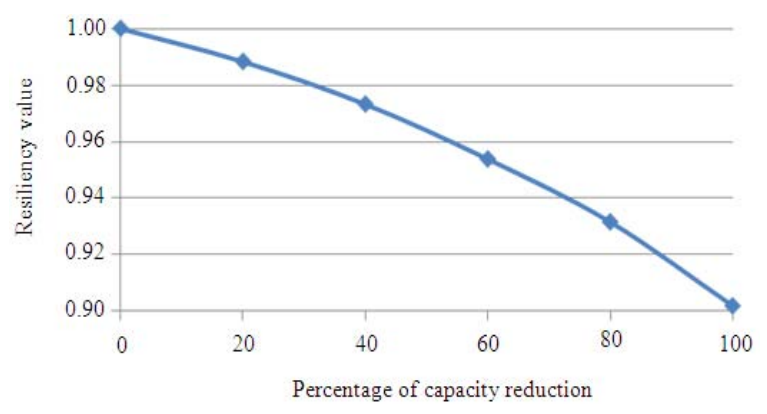

Fig. 7: Impact of Holland Tunnel on network resiliency

Re-routing the vehicles over other routes in the network improved the node-to-node resiliencies of the Holland Tunnel and the Queens-Midtown Bridge. In other cases, the resiliency has the same value; in such cases routing the vehicles through other routes will cause the traffic to congest elsewhere and will result in a decrease in the network travel time resiliency. Figure 7 shows the impact of disrupting the Holland Tunnel link

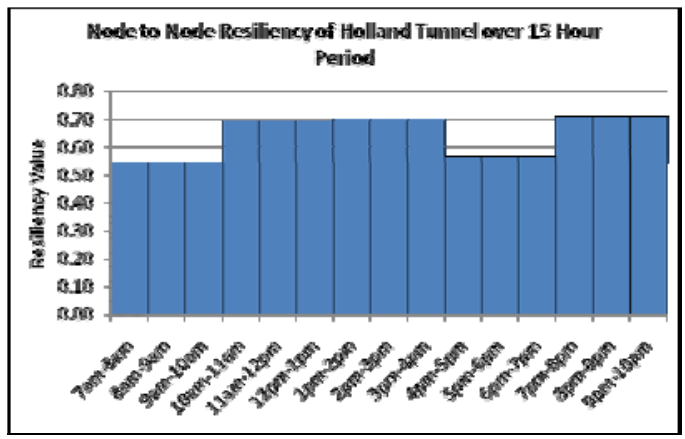

Fig. 8: Node to node resiliency of Holland Tunnel over $15 \mathrm{~h}$ periods at $80 \%$ capacity

on the network travel time. Total link disruption reduces the network travel time resiliency by $10 \%$.

The network demands are higher during rush hours periods such as 7-10 am and 4-7 pm than during the off-peak periods. The network is simulated over a $15 \mathrm{~h}$ time period each with its respective demand values (710 am and 10-1, 1-4, 4-7 and 7-10 pm), the result are shown in Fig. 8. It is assumed that the hourly vehicular traffic for each time period remains constant for the individual hourly time periods. The node-to-node resiliency over a defined period of time can be calculated as an integral over the time period.

Resiliency strategy evaluation: Road works or accidents in highways alter the behavior of traffic patterns and increase the fuel consumption of vehicles since the vehicles consume more fuel in congested traffic. In order to obtain a value for the extra cost of fuel consumed by the vehicles, it is assumed that the fuel consumption of vehicles is equivalent to the city fuel consumption. The fuel consumption values used for the calculation were based on city fuel consumption values for passenger cars and light trucks given by the Environmental Protection Agency, which are $21 \mathrm{mpg}$ and $17 \mathrm{mpg}$ respectively. In addition to the extra cost of fuel, the model takes into consideration the cost of $\mathrm{CO}_{2}$ mitigation and the cost of time.

The BPR function was used to estimate the travel time on the Holland Tunnel when the capacity is reduced by $60 \%$. The calculation showed that the travel time through the tunnel increases from $4 \mathrm{~min}$ to approximately $40 \mathrm{~min}$. This increase in time results in financial losses in terms of the extra cost of fuel, the cost of time and the cost of $\mathrm{CO}_{2}$ mitigation.

Severe disruptions in tunnels that are due to mechanical failures may take up to weeks to repair; it may be therefore beneficial to have an alternative mode of transportation such as ferries. This is particularly true 
for the location of the Holland tunnel since there are a fewer bridges and tunnels offering access to Manhattan on the west side of the island.

Using Eq. 14, the calculation show that for service disruptions of $60 \%$ capacity reduction, if the initial investment cost for converting the ferries to transport half the passengers is $\$ 350,000$ and the cost of operation is $\$ 50,000$, then the strategy is worth investing in for repair study that lasts more than 10 days in one year. It is important to note that the selected values for evaluating the resiliency strategies are not intended to obtain accurate figures for the cost of resiliency but rather to demonstrate the evaluation procedure.

\section{DISCUSSION}

This study proposes to measure the resiliency of infrastructure systems as the impact of disruptions in the performance measures of the system. In the transportation infrastructure system, one of the key performance measures is the travel time. Road disruptions causes traffic congestions, which could result in significant time delays. The resiliency of this type of network is measured as the ratio of the travel time under normal operating conditions to the travel time after the occurrence of a disruptive event. Because disruptions may last several hours, the proposed metric takes measures resiliency for the duration of the disruptive event. The advantage of this framework is that it allows stakeholders to measure the resiliency of the infrastructure system by linking the key performance measures to the network performance during disruptive events in a systemic manner.

\section{CONCLUSION}

The population of the island of Manhattan increases by more than $250 \%$ during the day; this fact signifies the importance of the transportation networks that connect Manhattan to the rest of the regions. Due to the large number of people travelling into and out of Manhattan every day, road obstruction in the entry points of Manhattan result in time delays as well as other negative environmental and financial impacts.

The NIRA framework proposes a methodology for assessing the resiliency of road-based network infrastructure systems that investigate the reaction of the system to disruptions and allows the decision makers to investigate the different resiliency strategies. The general methodology can be applied to any networked infrastructure system.
Resiliency is achievable through the application of active and proactive measures that reduce the vulnerability of the system and increase its adaptive capacity. One vulnerability reduction strategy is to reroute the traffic through other links in the network. This will however have an impact on the overall network travel time resiliency. Increasing the adaptive capacity can be in the form of influencing the traveler's mode choice. Improving the service level of other parallel systems such as ferries and trains will impact the choice for the mode of travel by increasing the probability that more travelers utilize the parallel systems.

Traditional decision analysis tools may be applied to help decision makers identify the effectiveness of various resiliency strategies that can be deployed in cases of emergency with prior knowledge of the initial investment and operation cost.

\section{REFERENCES}

Bruneau, M. and A. Reinhorn, 2007. Exploring the concept of seismic resilience for acute care facilities. Earthquake Spectra, 23: 41-62. DOI: 10.1193/1.2431396

Chang, C. and R. Mehta, 2010. Fiber optic sensors for transportation infrastructural health monitoring. Am. J. Eng. Applied Sci., 3: 214-221. DOI: 10.3844/ajeassp.2010.214.221

Chang, S.E. and C. Chamberlain, 2003. Assessing the role of lifeline systems in community disaster resilience. 1st Edn., Multidisciplinary Center for Earthquake Engineering Research, pp: 8.

Cohen, R., K. Erez, D. ben-Avraham and S. Havlin, 2001. Breakdown of the internet under intentional attack. Phys. Rev. Lett., 86: 3682-3685. DOI: 10.1103/PhysRevLett.86.3682

Heaslip, K., L. William and C. John, 2009. A methodology to evaluate transportation resiliency for regional networks. Proceeding of the 88th Annual Meeting of the Transportation Research Board, Jun. 11-15, Washington, D.C., USA.,

Horowitz, A.J., 1991. Delay-volume relations for travel forecasting, based on the 1985 highway capacity manual. Department of Civil Engineering and Mechanics, University of Wisconsin. https://pantherfile.uwm.edu/horowitz/www/Speed Volume1985HCMReport.pdf

Lee, E., 2008. Homeland Security and Private Sector Business Corporations' Role in Critical Infrastructure Protection. 1st Edn., CRS Press, ISBN: 9781420070781, pp: 281. 
Murray-Tuite, P.M., 2006. A comparison of transportation network resilience under simulated system optimum and user equilibrium conditions. Proceedings of the 38th Conference on Winter simulation, (WSC'06), Winter Simulation Conference, Monterey, Canada, pp: 1398-1405.

New Jersey Department of Transport, 2009. Roadway Information and Traffic Counts. State of New Jersey.

http://www.state.nj.us/transportation/refdata/roadw ay/

New York State Department of Transportation, 2009. Traffic Data Viewer. https://www.nysdot.gov/divisions/engineering/appl ications/traffic-data-viewer

Omer, M., R. Nilchiani and A. Mostashari, 2009. Measuring the resilience of the global internet infrastructure system. Proceedings of the 3rd Annual IEEE Systems Conference, Mar. 23-26, Vancouver, BC., pp: 156-162. DOI: 10.1109/SYSTEMS.2009.4815790

Shinozuka, M. and S.E. Chang, 2004. Modeling Spatial Economic Impacts of Disasters. 1st Edn., Springer Verlag, ISBN: 9783540214496, pp: 323.
Tilahunm, N. and D. Levinson, 2008. I-35W Bridge Collapse: Travel Impacts and Adjustment Strategies. University of Minnesota: Nexus Research Group. http://ideas.repec.org/p/nex/wpaper/i35wtravelimpactsandadjustmentstrategies.html

Transportation Research Board, 2000. Highway Capacity Manual. 1st Edn., Transportation Research Board, National Research Council, USA., ISBN: 0309067464

United States Environemntal Protectiona Agency, 2000. Emission Facts: Average Annual Emissions and Fuel Consumption for Passenger Cars and Light Trucks. http:/www.epa.gov/oms/consumer/f00013.htm

Werner, S.D., 1998. New developments in seismic risk analysis of highway systems. 30th UJNR Panel Meeting on Wind and Seismic Effects, Gaithersburg, Maryland. http://mceer.buffalo.edu/publications/resaccom/04sp01/15_werner.pdf 